Artigos

\title{
Afinidades eletivas: Foucault, a sociologia e os sociólogos
}

Alyson Thiago Fernandes Freire'

Resumo: Exploro neste ensaio o lugar da sociologia na trajetória e em alguns trabalhos de Michel Foucault, cotejando as referências que o filósofo francês realiza ao longo de sua obra à ciência da sociedade e a alguns sociólogos. A sociologia desponta nas análises do autor enquanto um tema lateral, ligado, sobretudo, à questão da emergência das ciências humanas e às transformações da economia do poder nas sociedades modernas. $\mathrm{O}$ artigo se propõe, também, a realizar uma leitura do pensamento foucaultiano, explicitando as afinidades e implicações teóricas, conceituais e temáticas com a sociologia. Por fim, discutimos a presença de Foucault na sociologia contemporânea e como alguns dos mais importantes sociólogos atuais se referiram ao seu trabalho.

Palavras-chave: Michel Foucault. sociologia. poder. ciências humanas.

\section{ELECTIVE AFFINITIES: FOUCAULT, SOCIOLOGY AND THE SOCIOLOGISTS}

Abstract: We explore on this essay the place of sociology in the path and in some works of Michel Foucault, comparing the references that the French philosopher made along his work to the science of society and some sociologists. The sociology emerges in the analysis of the author as a side issue, linked mainly to the question of the emergence of the human sciences and the transformations of power economy in

1 Instituto Federal de Educação, Ciência e Tecnologia do Rio Grande do Norte (IFRN) - Natal - Brasil alyson.freire@ifrn.edu.br 
modern societies. The article also proposes to conduct a reading of Foucault's thought, explaining the similarities and theoretical implications, conceptual and thematic with sociology. Finally, we discuss the presence of Foucault in contemporary sociology and how some of the most important current sociologists have referred to his work.

Keywords: Michel Foucault. sociology. power. human sciences.

Introdução

"Nada é evidente. Nada é gratuito. Tudo é construído"

(BACHELARD, 1996: 12).

Michel Foucault foi certamente um filósofo, um especialista em história das ciências. Mas, desde o início, seu itinerário intelectual o caracteriza como um filósofo de um tipo bastante singular. Foucault não se enquadra no modelo professoral do historiador e comentador das ideias e sistemas filosóficos do passado e do presente. Seu filosofar, por assim dizer, não é do comentário nem da exegese. Suas investigações conduziram-no a lidar com temas um tanto quanto "exóticos" e, em certo sentido, percebidos como de menor nobreza filosófica, como a história de instituições sociais muito particulares, como o hospital psiquiátrico, a clínica, a prisão. Mesmo seu interesse na prestigiosa história das ciências, que, na França de sua época, reunia nomes da envergadura de Gaston Bachelard e Georges Canguilhem, Foucault preferiu, no entanto, enveredar pelo estudo de ciências de menor prestígio e de status científico duvidoso, as ciências humanas.

Daí que, como notou Gilles Deleuze, o reconhecimento de Foucault como filósofo em sua época e entre os seus pares ter sido um assunto polêmico e ambivalente: para uns, trata-se, diz Deleuze, de "um farsante que não consegue apoiar-se em nenhum texto sagrado e que mal cita os grandes filósofos. Outros, ao contrário, dizem que algo de novo nasceu na filosofia e que esta obra tem a beleza daquilo que ela recusa: uma manhã de festa" (DELEUZE, 2005: 13).

Em seus trabalhos, Foucault apoiou-se em autores e metodologias não restritos ao campo da filosofia. Mais ainda: ele buscou enraizar os ditos problemas filosóficos relacionados à realidade, ao conhecimento, à verdade, à ética, ao sujeito, à liberdade no âmbito telúrico e demasiado humano das relações sociais, políticas, econômicas e culturais em que de fato se desenlaça o existir humano. ${ }^{2}$

2 Não se trata, de modo algum, de desmerecer ou diminuir a formação filosófica de Foucault. Suas biografias são enfáticas no que diz respeito à dedicação disciplinada de Foucault no estudo de filósofos como Kant, Nietzsche, Husserl e Heidegger. 
Em outras palavras, na história. Se, como afirma Foucault, a filosofia é "a forma cultural mais geral na qual poderíamos refletir sobre o que é o Ocidente" (FOUCAULT, 2002: 220), a condição indispensável para essa reflexão geral é problematizar e analisar o que é o Ocidente à luz das formas de exercício de poder e suas relações muito concretas com o corpo, com os prazeres, com a administração política, com a invenção de instituições especializadas e singulares, como o hospício, a clínica, a prisão, o confessionário.

Se, nos últimos trinta anos, o pensamento e a obra de Michel Foucault foram impulsionados para novas paragens nacionais e disciplinares, aumentando o poder de penetração e enraizamento do seu pensamento mundo afora, isso se deve muito, decerto, à maneira singular pela qual praticou a reflexividade filosófica. Seu faro de investigador fez com que fosse buscar as questões filosóficas e políticas que lhe interessavam menos nos comentários aos textos filosóficos consagrados e mais nos arquivos das bibliotecas, onde vasculhou documentos sobre aspectos e detalhes infames da história da sociedade moderna: registros de torturas, prisões de parricidas e hermafroditas no Século XIX, projetos arquitetônicos de presídios e hospitais, regulamentos de rotina e afazeres de internos, entre outros. Um "positivista feliz": para Paul Veyne, Foucault é o historiador em estado pleno, acabado, o primeiro a ser completamente positivista por ser o autor que empreendeu a revolução científica que todos os historiadores ansiavam e aguardavam (VEYNE, 2008: 239).

Essa reflexividade filosófica, munida do rigor das ciências especializadas e animada por uma atitude investigativa profundamente histórica e empírica, fez com que os estudos de Foucault resultassem em contribuições substantivas para diferentes áreas do conhecimento das relações e práticas humanas, e não apenas para o discurso filosófico. Seu pensamento transbordou os limites da filosofia, alcançando o campo das ciências especializadas e públicos extra-acadêmicos, inspirando, inclusive, grupos ativistas e militantes (HALPERIN, 1995).

Na sociologia, por exemplo, o "efeito Foucault" foi poderoso. A despeito das críticas que denunciam nas análises de Foucault uma perspectiva sociológica funcionalista do poder e do conhecimento (BRENNER, 1994), uma visão behaviorista da relação indivíduo/ sociedade (HONNETH, 2009) e uma compreensão redutora do sujeito e do desenvolvimento da modernidade como esvaziados de agência e reflexividade (GIDDENS, 2002), sua presença na sociologia é notável e intensa. Como outras disciplinas das ciências do homem, também a ciência da sociedade sentiu de maneira significativa o peso do "efeito Foucault". Ramos inteiros da sociologia têm no filósofo francês uma referência central e imprescindível: da sociologia da educação (VARELA; 
ALVAREZ-URIA, 1993) aos estudos de gênero e sexualidade (SEIDMAN, 2003) passando pela sociologia do crime e da punição (GARLAND, 1995), a sociologia das organizações (CLEGG, 1998) e a sociologia da saúde (PETERSEN, 1993) e do corpo (BRYAN, 1996).

No Brasil, a influência de Foucault se fez sentir inicialmente em trabalhos históricos, aliás, fora do campo dos historiadores profissionais (RAGO, 1995: 3), como o do filósofo Roberto Machado e do psiquiatra Jurandir Freire Costa. ${ }^{3} \mathrm{Em}$ sociologia, as pesquisas sobre violência, crime e segurança pública, de um lado, e gênero e sexualidade, do outro, são dois profícuos campos em que o arcabouço do filósofo francês é uma forte e constante referência. Nesses dois campos, poderíamos citar os trabalhos de Fernando Salla (2001), Sergio Adorno (2002) e Marcos Cesar Alvarez (2003). A propósito das pesquisas em gênero e sexualidade, Berenice Bento (2006), Antônio Cristian Saraiva Paiva (2007), Richard Miskolci (2009) e Alípio Sousa Filho (2009).

A presença de Foucault na sociologia se evidencia, também, de modo institucional, quer dizer, nos currículos de graduação e programas de pós-graduação em sociologia e ciências sociais no Brasil e no mundo. O nome do filósofo integra, inclusive, o rol das teorias sociológicas contemporâneas, como nos apresenta os grandes manuais da disciplina (CALHOUN et al., 2007: 287).

Os principais nomes das elaborações sociológicas mais recentes, Pierre Bourdieu, Anthony Giddens e Jürgen Habermas, não prescindiram do tratamento crítico dos aportes foucaultianos. Em seus empreendimentos de redefinir os rumos da teoria sociológica para além das velhas dicotomias que até então estruturavam a sociologia do pós-guerra, este "movimento de síntese", na precisa expressão de Jeffrey Alexander (1987), dedicou um espaço para discussão dos aportes do filósofo francês e de sua perspectiva sobre o mundo social.

Pierre Bourdieu, por exemplo, em As regras da arte, afiançou que, em se tratando da análise estrutural das obras culturais, é "sem dúvida em Michel Foucault que se encontra a formulação mais rigorosa” (BOURDIEU, 1992: 225). Giddens, por sua vez, considera que o trabalho de Foucault "talvez seja a contribuição mais significativa para a teoria do poder da administração desde os textos clássicos de Max Weber sobre a burocracia” (GIDDENS, 1998: 319) e que as "brilhantes inovações de Foucault colocam certas questões-chave de forma jamais pensada, anteriormente" (GIDDENS, 1993: 26).

3 Respectivamente, A danação da norma e Ordem médica e norma familiar, publicados em 1978 e 1979. Ambos tratam do papel do saber médico e das instituições disciplinares na constituição da ordem social na história do Brasil. 
O próprio Jeffrey Alexander considera Foucault, ao lado de ninguém menos do que Levi-Strauss, como um dos responsáveis por desencadear uma verdadeira revolução nas ciências humanas "ao insistir na textualidade das instituições e na natureza discursiva da ação humana” (ALEXANDER, 2000: 34).

Nesse sentido, é importante rastrear o "efeito Foucault" nas ciências sociais especializadas, como também problematizá-lo conforme as premissas e tradições desses campos, de sorte a suscitar posturas mais reflexivas e críticas em relação à sua recepção, aos usos e possíveis exigências de traduções disciplinares do modelo teórico foucaultiano. Da mesma maneira, é justo aceitar o desafio que a obra e a perspectiva teórica de Foucault coloca para as ciências sociais, isto é, submeter os pressupostos epistemológicos e a história das ciências sociais a uma crítica histórica e política radical.

Como uma modesta contribuição para esse empreendimento mais amplo, nesse ensaio, gostaria de explorar o lugar da sociologia na trajetória e em alguns trabalhos de Michel Foucault, cotejando as referências que o filósofo francês realiza ao longo de sua obra à ciência da sociedade e a sociólogos, assim como a posição de alguns sociólogos contemporâneos a respeito da obra do filósofo francês.

Qual, então, a relação de Foucault com a sociologia? Qual a posição da sociologia no seu pensamento e trajetória?

\section{0 lugar da sociologia na trajetória e no pensamento de Foucault}

A sociologia não figura, certamente, entre as grandes influências intelectuais do pensamento de Foucault. ${ }^{4} \mathrm{O}$ autor de Vigiar e Punir não era um entusiasta da sociologia enquanto uma disciplina científico-social rigorosa e capaz de revelar, tal como se supõe que as ciências naturais são capazes de fazê-lo, leis gerais do comportamento social e do desenvolvimento da sociedade - nem isso, de fato, lhe interessava quando se tratava de estudar as relações de força e sentido que os seres humanos constroem entre si na história.

Talvez, para Foucault, a sociologia nunca o interessou significativamente; não nutria por ela nenhuma grande paixão e admiração. Quiçá até concordasse com o seu amigo Paul Veyne quando este disparou, num libelo em favor da história, que a sociologia "não revelou nada que já não se soubesse, nenhuma

\footnotetext{
4 Entre as principais influências intelectuais que marcaram, em diferentes momentos, a formação e o itinerário intelectual de Foucault, podemos mencionar o pensamento filosófico de Kant, Nietzsche e Heidegger, a filologia comparada de Georges Dumézil e, sobretudo, a historiografia francesa dos Analles e a história da ciência dos epistemólogos franceses, como Georges Canguilhem (ERIBON, 1990).
} 
anatomia da sociedade, nenhuma relação causal que o bom senso já não conhece" (VEYNE, 2008b: 225). ${ }^{5}$

Entre as ciências sociais, mesmo a antropologia culturalista norte-americana goza de mais proeminência na formação do pensamento de Foucault do que a ciência da sociedade - aliás, como destaca Didier Eribon (1996), o papel da escola norte-americana de antropologia na formação de Foucault costuma ser pouco notado e lembrado. Foucault foi um leitor fascinado e empenhado dos trabalhos etnográficos e etnológicos, sobretudo no período da redação de seus primeiros ensaios e de sua tese. E não nos referimos aqui apenas ao ilustre Lévi-Strauss, o mais consagrado dos etnólogos. Antropólogos como Franz Boas, Ruth Benedict, Ralph Linton e Margareth Mead foram mais do que nomes em citações esparsas. Eles serviram como verdadeiras fontes de inspiração para temas, conceitos, e, em especial, para postura metodológica culturalista e de estranhamento diante de objetos pretensamente naturais, constantes e invariáveis, como a loucura, a personalidade, a sexualidade. Não por acaso, no começo da década de 1950, uma das propostas de tese de Foucault versava a propósito da "noção de cultura na psicologia contemporânea" (ERIBON, 1996: 66-7).

Retomando, o lugar modesto ocupado pela sociologia na formação, pensamento e obra de Foucault, explica-se, em parte, pela situação da sociologia francesa do pós-guerra. Os anos dourados das grandes expectativas por ocasião de sua fundação positiva com Durkheim e a profícua continuidade que os rebentos do autor das Regras do método sociológico, como Marcel Mauss, Maurice Halwbachs, François Simiand, Celéstin Bouglé, Fauconnet, Henri Hubert foram interrompidos bruscamente por mais uma guerra mundial. Em 1956, na França, existem menos de meia dúzia de cátedras de sociologia, um único laboratório de pesquisa e a antes prestigiosa e imponente Année Sociologique, luta para manter-se com publicações regulares, fato que não ocorre desde 1912 (BERTHELOT, 1991).

A frágil sociologia francesa dos primeiros anos da década de 1950 resume-se, grosso modo, à uma sociologia mais escolar e teórica, cujo principal nome à época é Georges Gurvitch, e, de outra, num cariz mais empiricista e sociográfico de sondagens de opinião e pesquisa em organizações, com Jean Stoetzel. Não

5 Convém fazer justiça a Paul Veyne para evitar mal-entendidos: sua crítica aparentemente demolidora da sociologia consiste, na verdade, numa crítica à história, de uma concepção estreita que a prende e limita ao estudo e descrição das sociedades do passado, deixando de lado, ou para a sociologia, a história da civilização contemporânea. Para Veyne, a sociologia é história, sem ter esse nome, ela faz história, sem se reconhecer com tal. A ambição do historiador nesse texto é sugerir uma história completa, total, "pois descrever o concreto é um trabalho infinito" (VEYNE, 2008b: 217). 
sendo, com efeito, atrativa para os ambiciosos e cultivados jovens "normaliens" do início dos anos 1950. Para estes, a sociologia lhes parecia uma disciplina menor, marginal. Não gozava, no campo acadêmico francês da época, do mesmo prestígio e status que a filosofia e a história de então usufruíam. Até começo dos anos 1960, a sociologia estava alojada como uma disciplina dentro dos programas de filosofia na França (BERTHELOT, 1991).

Ao longo de sua obra, Foucault pouco recorreu, de maneira explícita, a trabalhos, autores e conceitos da sociologia. Citações a esse propósito eram esparsas, e, muitas vezes, surgiam em tom crítico. Em um dos seus primeiros livros, Doença Mental e Psicologia, Foucault, em sua crítica epistemológica e histórica contra as pretensões e concepções essencialistas da psicologia e da medicina somática acerca da enfermidade mental enquanto uma entidade objetiva e orgânica, reserva algumas páginas para criticar a noção de "patológico" em Durkheim. Para Foucault, o sociólogo francês possuía um entendimento essencialmente negativo e virtual do fenômeno patológico, tratando-o como algo "anômalo" e "irregular" em relação à ordem social presente, um resquício ou um anúncio das etapas de desenvolvimento da sociedade. Uma concepção, sustenta Foucault, ao mesmo tempo, evolucionista e estatística que deixava de fora o principal.

$\mathrm{Na}$ interpretação de Foucault, a raiz do equívoco radica na "ilusão cultural" que faz com que os cientistas, de médicos à sociólogos, tomem o modo de relação cultural do ocidente moderno com a doença e o patológico como se fosse a própria natureza e sentido destes últimos. E isto porque, conclui Foucault:

[...] nossa sociedade não quer reconhecer-se no doente que ela persegue ou que encerra; no instante mesmo em que ela diagnostica a doença, exclui o doente. As análises de nossos psicólogos e sociólogos, que fazem do doente um desviado e que procuram a origem do mórbido no anormal, são, então, antes de tudo, uma projeção de temas culturais (FOUCAULT, 1984: 74).

Décadas mais tarde, numa conferência chamada "As malhas do poder", Foucault volta a criticar Durkheim. Dessa vez, por identificar nele, uma sociologia e etnologia do poder fechadas no problema da proibição e da regra (FOUCAULT, 2012: 170).

As referências a outro importante e clássico sociólogo, Max Weber, são mais ambíguas, pois, ambos os autores compartilham, em certa medida, alguns pressupostos e problemas em comum, como: a preocupação com as singularidades históricas, as posturas metodológicas nominalistas e não-essencialistas diante da realidade e, por último, o interesse pelas formas de dominação e poder como aspectos onipresentes na vida social, principalmente no que diz respeito à estreita ligação entre racionalidade, poder e modernidade. 
É sobre este último ponto que o filósofo francês evoca, de maneira ambígua, sua relação com o sociólogo alemão. Por um lado, Foucault (2011: 268) situou sua trajetória e empresa intelectual como tributárias de uma forma de reflexão e interrogação da atualidade, que, desdobrada da tradição crítica de Kant, tem em Max Weber um de seus herdeiros, ao lado de outros expoentes como Nietzsche e a Escola de Frankfurt. Reconhece também no que diz respeito à definição do tema do asceticismo - estudado por Weber no âmbito das seitas protestantes e da emergência do capitalismo moderno, e por Foucault nas práticas ascéticas das escolas filosóficas greco-romanas e do cristianismo antigo e medieval -, uma proximidade quanto ao significado dado pelo sociólogo alemão; ainda que mais geral, diz Foucault, "está, em todo o caso, na mesma linha" (FOUCAULT, 2006: 265).

Não obstante o reconhecimento dessas afinidades, Foucault demarca diferenças de suas análises das de Max Weber; primeiro, em relação ao asceticismo, sustenta que lhe interessa mais do que entender a que parte de nós que devemos renunciar para adotar um comportamento racional e regular nossa ação, questão esta que seria, segundo Foucault, a de Weber. Para o filósofo francês, interessa, por sua vez, a questão inversa: "como certos tipos de saberes sobre o si são advindos do preço a pagar por causa de determinadas formas de proibição? O que se deve conhecer de si a fim de aceitar a renúncia?” (FOUCAULT, 2010: 1).

Quanto à racionalização em Weber, trata-se de se distanciar porque, ao contrário deste, conforme o próprio Foucault, em vez de conceber a noção de racionalização como um conceito universal e transhistórico, capaz de apreender as grandes tendências de desenvolvimento que singularizam uma civilização e período histórico, isto é, considerar como um todo a racionalização da sociedade e da cultura, trata-se de "analisá-la como um processo em vários campos; cada um dos quais com uma referência a uma experiência fundamental: loucura, doença, morte, crime, sexualidade" (FOUCAULT, 1995: 233).

A nosso ver, a visão de Foucault a respeito do conceito de racionalidade/ racionalização em Weber é bastante parcial e simplificadora. Se em sua sociologia da religião e comparada acentuam-se, de fato, os aspectos mais macrossociológicos do conceito de racionalização, no sentido de uma matriz civilizatória que exprime direções de desenvolvimento de significado e validade universais para uma cultura (WEBER, 2001), isso não significa que o sociólogo alemão compreendia a racionalização como um conceito necessariamente globalizante. Por diversas vezes, nos marcos de sua teoria da ação e da diferenciação das esferas de valor, Weber ressaltou a pluralidade das formas de racionalização e de racionalismo, sejam elas entre culturas ou mesmo internas à mesma cultura 
e sociedade, pois esses conceitos tratam, também, de compreender a gênese e a institucionalização de formas racionalizadas de condutas e ações particulares as quais podem remeter aos mais diversos domínios do agir e sentir humano. Em suas palavras: "há, por exemplo, racionalizações da contemplação mística (...), bem como racionalização da economia, da técnica, do trabalho científico, da educação, da guerra, da justiça e da administração. Cada um desses âmbitos pode 'racionalizar-se' sob pontos de vista e objetivos últimos da maior diversidade, e o que é 'racional' para um pode, ao ser observado por outro, ser 'irracional'. De maneira que há ocorrido racionalizações dos tipos mais diversos e nos diferentes âmbitos da vida em todas as culturas" (WEBER, 2001: 20-1). ${ }^{6}$

Com a crítica ao conceito e ao tratamento weberiano de racionalização, Foucault, na verdade, busca destacar sua própria concepção de racionalidade, mais plural e regional, e definida conforme a interpendência estratégica e singular produzida entre saber, poder e verdade em um determinado campo de problematização das práticas sociais. No esquema teórico foucaultiano, racionalidade e dominação estão referidos a domínios e regimes de práticas específicos e concretos, e, por isso, articulam-se de diversos modos a depender dos contextos de ação, das condições de emergência e formação desses contextos, discursos de poder e das tecnologias políticas empregadas.

O que o nexo teórico entre racionalidade e dominação revela são os diferentes dispositivos de poder e suas formas de problematização singulares do ser humano. Quer dizer, as conexões interdependentes entre saber e poder, os regimes de verdade provisórios que se consolidam, não sem luta, resistência e ambiguidades, em campos de experiência diversos do existir humano e seu cotidiano, constituindo e colocando em marcha diferentes e múltiplas formas de exercício de poder. A dominação, com efeito, não é pensada em chave única, e a racionalidade, longe de explicitar os fundamentos de uma formação social e seu desenvolvimento histórico particular, exprime a complexidade e a heterogeneidade do social.

Embora existam pertinentes similaridades entre Weber e Foucault quanto às conexões entre as relações de poder e a vida social, e o próprio Foucault incluiu-se numa tradição de pensamento que tem o sociólogo alemão como um dos representantes, foi em outro pensador social alemão que, na verdade, Foucault buscou a inspiração para abordar o poder em termos do funcionamento

6 Weber estudou ainda as formas de racionalização da música e do erotismo; para mais detalhes, ver, respectivamente: WEBER, Max. Os fundamentos racionais e sociológicos da música. São Paulo, Edusp; WEBER, Max. Rejeições religiosas do mundo e suas direções. Ensaios de sociologia. Org. H. H. Gerth e C. Wright Mills. Rio de Janeiro, Guanabara, pp. 371-410, 1982. 
dos seus mecanismos positivos e capilares na realidade social. Para, talvez, a surpresa e estranhamento de alguns, trata-se de Karl Marx. Mais precisamente, de acordo com o próprio Foucault, o livro II de O Capital:

Em suma, o que podermos encontrar no livro II de O Capital, é, em primeiro lugar: não existe um poder, mas muitos poderes. Poder quer dizer formas de dominação, formas de sujeição, que funcionam localmente, por exemplo, no ateliê, no exército, em uma propriedade de tipo escravagista ou em uma propriedade onde há relações servis (FOUCAULT, 2012: 172).

No mesmo texto, Foucault sustenta que gostaria de fazer a história dos poderes no Ocidente, retomando exatamente os insights do Capital sobre heterogeneidade das formas de poder, mas se afastando, por outro lado, de tudo que o foi acrescentado e reescrito em seguida acerca da primazia do Estado, da infraestrutura material, da dominação de classe e do caráter peculiar da superestrutura jurídica (FOUCAULT, 2012: 175).

O tom crítico e o espaço relativo que parece conferir à sociologia, não significa que Foucault a desconhecia e, muito menos, a ignorava. Em meados dos anos 1960, Foucault participou das discussões sobre a reforma do ensino de filosofia na França. No documento reformador que elaborou, ele incluiu a disciplina de sociologia no programa curricular, tanto do ensino "secundário" quanto do ensino superior. No ensino superior, ao lado de outras disciplinas das ciências humanas, como "história das ideias políticas e morais", "psicologia infantil", a sociologia aparece como uma matéria do segundo ano do primeiro ciclo, sendo a ela destinada a carga horária de duas horas. Seu objetivo, como destaca Didier Eribon, é servir como uma matéria preparatória para as disciplinas especializadas do ensino base de filosofia (ERIBON, 1996: 183-185).

Ainda na década 1960, Foucault participa de um debate no rádio com o sociólogo Raymond Aron para, inicialmente, discutir o livro recém-lançado deste último, Etapas do Pensamento Sociológico. O mote inicial consistia, mais especificamente, em debater o lugar de Montesquieu no pensamento social. No entanto, o debate, rapidamente, se desloca para as controversas teses de Foucault, apresentadas em As palavras e as coisas, que suscitou enorme polêmico no mundo intelectual francês do fim dos anos 1960. (ARON; FOUCAULT, 2007).

Retomando, o seu mais conhecido biógrafo também alude, em uma nota de rodapé, que, muito provavelmente, os insights de Foucault sobre o nexo saber/ poder, isto é, os efeitos de poder investidos nos saberes em nossa sociedade, foram colhidos na sociologia do sistema escolar de Pierre Bourdieu 
e Jean-Claude Passeron, nas obras Le Héritiers, de 1964 e La Reproduction, de 1970 (ERIBON, 1996: 192).

Curiosamente, nos livros de Foucault praticamente não encontramos citações aos trabalhos de Bourdieu, a despeito de ambos partilharem bases epistemológicas (Bachelard e Canguilhem) e interesses de conhecimento bastante próximos, de serem contemporâneos, colegas no Collège de France e amigos pessoais. Numa das poucas passagens a que se refere à Bourdieu, Foucault, numa entrevista, reporta-se exatamente às bases epistemológicas a que nos referimos: "Mas suprimam Canguilhem e vocês não apreenderão o que há de específico em sociólogos como Bourdieu, Castel, Passeron, e que os marca tão intensamente no campo da sociologia" (FOUCAULT, 2000a: 353 ).

De fato, Foucault parece se interessar pela sociologia enquanto uma questão residual ou lateral a outros problemas mais fundamentais que aborda. Contudo, sejam questões sociológicas seja a própria sociologia enquanto ciência, ela parece atravessar temas que interessam profundamente a Foucault, como a emergência das ciências humanas e as formas de exercício do poder nas sociedades modernas. Vejamos.

A problematização da emergência do campo epistemológico das ciências humanas na episteme moderna levou Foucault a analisar as condições de possibilidade do discurso sociológico sobre o homem enquanto positividade - problema arqueológico abordado em As Palavras e as Coisas. Neste livro, sustenta o filósofo, a sociologia emerge, na episteme moderna, tal como as demais ciências humanas, definida pela relação e o domínio discursivo aberto pela biologia, economia e filologia no espaço do saber. ${ }^{7}$ Assim,

a 'região sociológica' teria encontrado o seu lugar lá onde o indivíduo que trabalha, produz e consome se confere a representação da sociedade em que se exerce essa atividade, dos grupos e dos indivíduos entre os quais ela se reparte, dos imperativos, das sanções, dos ritos, das festas e das crenças mediante os quais ela é sustentada ou regulada (FOUCAULT, 20oob: 491-2).

Nos anos 1970, a reflexão genealógica foucaultiana atinge a sociologia e o discurso sociológico, abordando-os como efeitos de dispositivos de poder de disciplinamento e normalização dos indivíduos, em particular do "indivíduo delinquente" e dos fenômenos de "população". Como as ciências humanas em geral, a gênese social da sociologia tem suas raízes nas instituições modernas

7 Para mais detalhes, ver o último capítulo de As Palavras e as Coisas, mais especificamente a seção o “Triedro dos saberes”. FOUCAULT, Michel. As palavras e as coisas. São Paulo. Martins Fontes, 2000. 
disciplinares - como a prisão, a escola, a oficina - e nas técnicas de poder a partir dos quais se formou o jogo moderno das coerções sobre os corpos, os gestos, os comportamentos individuais e coletivos (FOUCAULT, 1988; 2004).

Estudando os mecanismos específicos do exercício do poder disciplinar, Foucault destaca o exame como uma das "formas de análise que deram origem à Sociologia, à Psicologia, à Psicopatologia, à Criminologia, à Psicanálise" (FOUCAULT, 2005: 12).

Isso porque o exercício dessa técnica de poder proporciona a possibilidade de obtenção e constituição de saber sobre indivíduo. O exame converte o indivíduo num objeto suscetível de observação, descrição e análise, ao mesmo tempo em que o transforma numa regularidade por meio do registro documental de seu comportamento, desempenho, qualidades, deficiências, histórico (FOUCAULT, 2004).

De modo similar, encontramos na análise de Foucault a respeito da formação do dispositivo da sexualidade, e a explosão discursiva de produção de saber que fez "do sexo não somente uma questão leiga, mas um negócio de Estado" (FOUCAULT, 1988: 110), uma breve menção à construção do campo de problemas da sociologia.

O filósofo francês identifica, entre a metade do Século XVIII e ao longo do Século XIX, o aparecimento de novas práticas estatais e institucionais de administração do corpo social em que a sociedade é concebida como um organismo vivo, uma "massa viva" de indivíduos, sujeita a processos e ocorrências de natureza biológica que cumpre conhecer, regular e integrar em sua diversidade, regularidade, utilidade e prejuízos para os aparelhos produtivos e políticos. Essas novas práticas, que Foucault chamará de biopolítica, fazem surgir todo um conjunto novo de problemas e preocupações públicas, fenômenos biológicos próprios à vida coletiva e individual, como mortalidade, natalidade, crescimento demográfico, longevidade, nível de saúde, morbidade, habitação, salubridade, (FOUCAULT, 1988: 132).

Este é um poder, um "biopoder", que faz os indivíduos ocidentais aprenderem progressivamente "o que é ser uma espécie viva num mundo vivo, ter um corpo, condições de existência, probabilidade de vida, saúde individual e coletiva, forças que se podem modificar e um espaço em que se pode reparti-las de modo ótimo" (FOUCAULT, 1988: 134).

O campo empírico que novos saberes científicos, como a sociologia e outras ciências, tomaram para si como seus terrenos de investigação positiva não caiu do céu, pronto, nem foi o resultado imediato de operações epistemológicas de heróis fundadores ou do acúmulo de ideias e investimentos intelectuais 
preparatórios. Na verdade, o que a discussão de Foucault sobre a biopolítica e o biopoder nos mostra é que esse campo empírico foi produto de uma transformação da economia do poder e do surgimento de uma nova racionalidade política de administração e intervenção social. Ou seja, para emergência do estudo dos fatos sociais foi preciso o aparecimento de determinadas condições políticas e institucionais de possibilidade que converteram fenômenos vitais da população em objetos de cálculos estratégicos e em realidades sociopolíticas relevantes. Por isso, afirma Foucault:

Não deve surpreender que o suicídio - outrora crime, pois era um modo de usurpar o direito de morte que somente os soberanos, o daqui debaixo ou o do além, tinham o direito de exercer - tenha se tornado, no decorrer do século XIX, uma das primeiras condutas que entraram no campo da análise sociológica [...] (FOUCAULT, 1988: 130).

A referência à sociologia é, com efeito, realizada nos marcos da "analítica dos poderes e das fórmulas de dominação" individuais e coletivas engendrados pela sociedade moderna. Uma origem pouco nobre. No entanto, bastante rica para estudos sobre a sociogênese da sociologia e para novas ideias e pesquisas em sociologia do conhecimento que almejem ir além do importante gesto durkheimiano de enraizar as estruturas do pensamento na morfologia social em favor da problematização das condições históricas e políticas que tornam possíveis formas de conhecimento específicas.

Não obstante essa visão crítica e bastante impiedosa a propósito da emergência da sociologia, não significa que o projeto intelectual de Foucault seja estranho ao campo sociológico ou represente uma recusa sistemática da sociologia como campo de saber. Foucault compartilha com a sociologia um conjunto de objetos e temas próprios e consagrados desse campo de estudo. Temas, como disciplina, ascese, punição, normas, práticas divisoras do normal e do patológico, a medicalização, Razão de Estado, instituições sociais, corpo, controle social, delinquência, desvio social são questões largamente trabalhadas em sociologia nas suas diferentes escolas e tradições.

\section{Afinidades eletivas e a influência foucaultiana sobre a sociologia contemporânea}

A produção intelectual de Foucault possui algumas convergências e afinidades que, a nosso ver, justificam, de maneira consistente, o intento de uma aproximação ao seu pensamento a partir de um ângulo sociológico. O historiador Paul Veyne não deixou de perceber uma certa relação do projeto geral de Foucault 
com o que ele intitulou como uma "história sociológica das verdades", título que dá a um dos capítulos do seu mais recente livro sobre Foucault (VEYNE, 2009).

A inquietação de Foucault com a gênese das instituições que originaram o indivíduo moderno, ou com as formas de racionalidade estruturante das práticas sociais mais familiares das sociedades modernas, conduziu o seu trabalho a um campo de problemas muito próximo da sociologia. A démarche espaço-temporal privilegiada do programa de investigação foucaultiano está inscrita, sobretudo, nas sociedades burguesas modernas da Europa dos Séculos XVIII e XIX, assim como os trabalhos pioneiros e formadores da tradição sociológica clássica, formada por Marx, Durkheim, Simmel e Weber (NISBET, 1969). A modernidade como questão é um mote tão contundente na sociologia que, por exemplo, Anthony Giddens define a sociologia não como a disciplina genérica que estuda as sociedades humanas em geral, mas, sim, como a ciência que investiga e analisa as sociedades modernas em particular (GIDDENS, 1991).

O papel do conhecimento, ou, como prefere Foucault, do saber como uma questão estratégica na estruturação da vida coletiva e seus sistemas de ideias e dominação é outro ponto fundamental de cruzamento entre as problemáticas foucaultianas e a sociologia. Nessa seara, Foucault se aproxima de um conjunto de sociólogos para os quais o conhecimento constitui uma instância de atividades central para compreender as relações de poder, as assimetrias e os conflitos das sociedades capitalistas avançadas, como Daniel Bell, Pierre Bourdieu e Ulrich Beck.

Podemos encontrar na obra do filósofo francês uma sociologia do conhecimento em que o saber como formação discursiva goza de primazia e pode ser analisado em suas próprias regras e dinâmica, como em As palavras e as coisas. Mas, também, encontramos análises em que o saber, o discursivo, as formas de conhecimento são tecidas e estão inscritas nas estruturas sociais, nas estratégias políticas mais globais, nas instituições de poder e nas práticas sociais de uma sociedade. $\mathrm{O}$ saber, o estudo de um campo de saber, com seus objetos constituídos (a loucura, a sexualidade, a delinquência, a infância), seus conceitos, suas abstrações, seus instrumentos, suas instituições constituem, na analítica genealógica foucaultiana, uma verdadeira chave de leitura da economia de poder de uma sociedade e seus sistemas de sujeição, pois, "não há relação de poder sem a constituição correlata de um campo de saber, nem saber que não suponha e não constitua ao mesmo tempo relações de poder" (FOUCAULT, 2004: 30).

A temática das instituições disciplinares e de enclausuramento abordadas de maneira tão desconcertante em História da Loucura e em Vigiar e Punir, é objeto de uma pesquisa sociológica clássica, realizada pelo sociólogo canadense 
Erving Goffman, em meados dos anos 1950, sobre o que este classificou de "instituições totais": manicômio, conventos, colégios internos, orfanato, quartéis. Ainda no âmbito da sociologia norte-americana, um pouco mais tarde, no começo dos anos 1960, temos estudos inovadores sobre a produção social do desvio e da "anormalidade" comportamental, como os trabalhos de Howard S. Becker com usuários de maconha e músicos de jazz. A questão do disciplinamento dos indivíduos e do autocontrole na relação entre poder e corpo reluz fortemente, e, também abordados numa perspectiva histórica, nas obras de gigantes da sociologia, como Max Weber e Norbert Elias. ${ }^{8}$ A lista de problemáticas afins que aproxima sociólogos e Foucault é ampla e significativa.

De um ponto de vista mais teórico e conceitual, encontramos na empresa intelectual foucaultiana uma série de conceitos que, há muito, compõe o léxico e o patrimônio conceitual da disciplina; racionalidade, poder, dominação, instituição, ação, conhecimento, discurso, prática social. Epistemologicamente, algumas das premissas centrais da perspectiva sociológica, como a desnaturalização dos objetos, a pluricausalidade dos fenômenos humanos, a ênfase nas práticas sociais, a perspectiva sobre o agente enquanto corpo engajado e socialmente produzido por constrangimentos materiais, a problematização das pressuposições familiares sobre a realidade e a ruptura com o senso comum, entre outras, encontram no trabalho de Foucault um tratamento e desenvolvimento constante e singular.

Por isso, o pensamento foucaultiano inspirou e influenciou uma variedade de sociólogos e pesquisas sociológicas. Alguns importantes sociólogos da segunda metade do Século XX escreveram obras relevantes num diálogo direto com o filósofo de Poitiers e sob o sol da pesquisa arqueogenealógica foucaultiana. É o caso de Jacques Donzelot e seu livro Polícia das Famílias, dos primeiros trabalhos de Robert Castel sobre a ordem psiquiátrica e o papel de controle social na vida cotidiana realizado pela psicanálise, ${ }^{9}$ assim como o seu clássico As

8 De acordo com Spierenburg, Foucault traduziu, para o seu uso pessoal, o livro de Norbert Elias, $A$ solidão dos moribundos. Ainda segundo o autor, o interesse do filósofo francês na obra do sociólogo alemão teria, provavelmente, relação com o sentimento de sua própria morte iminente. Para maiores detalhes, ver: SPIERENBURG, P. C. Punishment, power, and history: Foucault and Elias. Social science history, Durham, v. 28, n. 4, p. 607-636, 2004.

9 O trabalho de Robert Castel, $O$ psicanalismo, foi, inclusive, elogiado por Foucault nas conferências que este realizou no Rio de Janeiro na década de 1970: "Ele (Castel) tenta retomar essa idéia de que, em última análise, a psicanálise procura apenas deslocar, modificar, enfim, retomar as relações de poder que são as da psiquiatria tradicional. Eu tinha expresso isso desajeitadamente no final da História da Loucura. Mas Castel trata o assunto muito seriamente com documentação, sobretudo sobre a prática psiquiátrica, psicanalítica, psicoterapêutica numa análise em termos de relação de poder" (FOUCAULT, 2005: 150). 
metamorfoses da questão social, uma verdadeira genealogia da sociedade salarial e suas formas de individuação. Por último, cabe lembrar o sociólogo norte-americano Richard Sennett, o qual reconhece, nos agradecimentos de seu livro Carne e pedra, sua dívida para com Michel Foucault, com quem iniciou no fim de 1970 pesquisas sobre a história do corpo (SENNETT, 2003: 12; 25).

Outros sociólogos, inclusive, concedem um lugar a Foucault na chamada "virada praxiológica" na teoria social, isto é, o conjunto de autores e teorias sociais que alçaram as práticas sociais como o quadro teórico-metodológico de análise do mundo social e da ação social, do qual fazem parte sociólogos como Bourdieu e Giddens. O filósofo francês possui, também, um assento reservado na intitulada "sociologia crítica" (POWER, 2011).

Mais contemporaneamente, sociólogos como Mitchel Dean e Nikolas Rose desenvolveram abordagens profundamente inovadoras e operacionais em termos de pesquisa exatamente valendo-se da caixa de ferramentas foucaultiana. O primeiro com investigações genealógicas sobre os discursos e as formas liberais de governo da pobreza e de assistência aos mais pobres e desempregados, ao passo que o segundo, por sua vez, tem desenvolvido há mais de duas décadas pesquisas empíricas sobre as tecnologias de governo e subjetivação das condutas nas sociedades contemporâneas presentes em saberes experts, como psicologia, psiquiatria biológica e neurociência (DEAN, 1999; ROSE, 1996, 2007).

Mesmo um sociólogo como Bernard Lahire, notório e intransigente defensor das ferramentas intelectuais e dos predicados distintivos que definem o ofício do sociólogo, reconhece em Foucault um "espírito sociológico" invejável e um autor que fala a mesma "língua dos sociólogos". Para Lahire, Foucault foi, sem dúvida alguma, o filósofo francês mais próximo e familiar ao universo de pensamento próprio dos investigadores em ciências sociais - sociólogos, antropólogos e historiadores, sobretudo (LAHIRE, 2006a: 109).

Para Lahire, aliás, as orientações intelectuais do trabalho de Foucault foram fundamentais em sua formação como sociólogo por duas razões: primeiro, para contrabalancear a influência de Pierre Bourdieu em seu pensamento e, segundo, por servir como uma verdadeira proteção contra as formas sociológicas de pensar mais rotineiras (LAHIRE, 2006a: 110; 112). Lahire celebra na obra de Foucault o tratamento original que este conferiu ao tema do sujeito, pensado a partir de uma duplicidade do laço social. Para Lahire, além de articular as condições políticas e culturais de sua constituição dentro de contextos históricos bem determinados, Foucault se esforça por articular, sob os mesmos princípios teóricos e metodológicos anteriores, a relação do sujeito consigo mesmo. Ou seja, segundo a leitura do sociólogo francês, o autor de Vigiar e Punir constrói 
ao longo de sua obra estudos e conceitos que exprimem o vínculo íntimo entre, por um lado, as formas de governo do outro, ou seja, as formas de exercício do poder sobre o outro e as formas de governo e domínio de si (LAHIRE, 2006a: 117). Nota-se, nesse ponto, aliás, como Lahire se apropriou de Foucault para elaborar o seu próprio projeto de "sociologia em escala individual", isto é, compreender sociologicamente as biografias e singularidades individuais a partir dos modos plurais pelos quais o social é interiorizado nos e pelos indivíduos.

Em suas palavras, Foucault seria um "filósofo impuro", munido de um ethos de investigador, pois sua reflexão e conceitos estão alicerçados em denso material empírico (LAHIRE, 2006a: 114). Didier Eribon, em sua biografia sobre Foucault, destaca a obstinação empírica do filósofo francês cujo hábito de ir diariamente à Biblioteca Nacional, cultivado já nos inícios dos anos 50 por ocasião de sua pesquisa de tese, tornou a Biblioteca Nacional "um dos lugares onde Foucault passou o maior número de horas de sua vida" (ERIBON, 1990: 54).

De fato, o ethos de investigador em Foucault é mais do que uma disposição intelectual de fundamentar empiricamente suas pesquisas e análises. Impressiona, igualmente, a habilidade com que manuseia fontes de documentos incrivelmente diversas. Em seus livros, o corpus empírico é formado por pinturas, obras de teatro, novelas literárias, taxonomias naturalistas, manuais terapêuticos, textos filosóficos e religiosos, códigos jurídicos, literatura pedagógica, decretos administrativos, planos e disposições arquitetônicas, entre outros documentos. A heterogeneidade de fontes responde às próprias exigências e pressupostos da noção de multicausalidade com que trabalha e de sua abordagem nominalista e radicalmente histórica na investigação do que é o coração de seu projeto filosófico, qual seja, "a genealogia do sujeito na civilização ocidental" (FOUCAULT, 2006a: 95).

Não é preciso muito esforço para encontrar em Foucault alguns dos pressupostos epistemológicos básicos da sociologia. Mesmo uma leitura superficial e introdutória de sua obra logo se depara com posturas analíticas e metodológicas bastantes familiares ao ofício do sociólogo. Por exemplo, a ruptura com as pré-noções ou com senso comum, que de Emile Durkheim à Pierre Bourdieu constitui uma verdadeira pedra de toque da epistemologia das ciências sociais.

O projeto arqueogenealógico foucaultiano não é outra coisa senão uma problematização radical da evidência de nossas práticas, valores, crenças e normas. Problematização que, na esteira de Kant, Nietzsche e Bachelard, assume a forma da investigação histórica enquanto crítica do presente e das naturalizações que transformam o que é singular, histórico e contingente em evidências 
incondicionadas ou em universais antropológicos. No vocabulário foucaultiano, em verdades aceitas como tais.

Foucault questiona a naturalização de um conjunto de ideias, esquemas pré-estabelecidos e práticas que foram institucionalizadas e aceitas social e culturalmente como verdadeiras porque se valeram como sendo discursos de verdade: a loucura como patologia mental, o internamento terapêutico, a prisão como modelo de punição, o sexo como lugar da identidade e verdade do sujeito, a prática da confissão, entre outras. No mesmo sentido, Foucault coloca em suspeição um conjunto de figuras de subjetividade com as quais nos acostumamos como verdadeiras evidências empíricas do universo humano e de nosso cotidiano; o louco, o doente mental, o delinquente, o perverso, a histérica, o monstro humano, o anormal...

Nesse ponto em particular, Foucault não está muito distante da empresa teórica do sociólogo Pierre Bourdieu. Tanto num e como no outro, trata-se de abordar e demonstrar os fatos humanos, isto é, os produtos da ação e do pensamento humano, sejam eles instituições sociais, ideologias, formas de classificação e divisão do mundo sejam relações e práticas sociais cotidianas enquanto fatos sociais arbitrários, singulares e contingentes, retirando o véu de evidência e de coisa natural que recobrem os olhos contemporâneos leigos e doutos. ${ }^{10}$

No caso de Foucault, a ruptura com as pré-noções tem como alvo um ente mais concreto e empiricamente mais identificável do que o chamado "senso comum", qual seja: os conhecimentos científicos e os saberes institucionais. É sobre estes que o filósofo francês lança o seu exercício da suspeita e sua crítica histórica radical, revistando, num trabalho arqueológico, empoeirados documentos, tratados científicos, planos, programas, para compreender como os saberes aparecem, se impõem e se transformam, tanto num nível discursivo quanto num nível não-discursivo, compondo com as relações de poder estratégias sociais e políticas de dominação, exclusão, desqualificação.

Se a sociologia, conforme definiu Durkheim, é "a ciência das instituições, de sua gênese e funcionamento", então os sociólogos tem em Foucault uma referência fundamental. Não somente porque a análise das instituições sociais, de

10 O trabalho sociológico de Bourdieu empenha-se em desvendar os mecanismos históricos e o trabalho institucional de eternização das "verdades do mundo social" sem deixar de analisar a partir de que relações de força e de sentido determinadas frações de classe e instituições conseguem impor suas definições e significados da realidade como sendo verdadeiras, universais e naturais a todo o restante da sociedade. É sob esse pano de fundo que podemos compreender o impulso teórico básico que impeliu o sociólogo, por meio de conceitos como "arbitrário cultural" e "poder simbólico", a se lançar contra a naturalização da divisão social entre os sexos e das ideologias do êxito escolar como mérito e do bom gosto como dom natural. 
sua história e funcionamento, é uma verdadeira constante na obra foucaultiana. Mais do que isso: Foucault desenvolveu uma perspectiva de análise que, investigando as instituições, não se deixa confinar por elas, isto é, não permitiu que as interrogações e questões que lhe interessavam se limitassem às fronteiras institucionais, isto é, ao universo social restrito de suas práticas, especialistas, procedimentos e atuação.

As práticas de poder e os saberes que constituem as instituições, em suas regras, arquiteturas, discursos, atravessam e circulam uma variedade de espaços institucionais e não-institucionais. Elas condicionam e organizam relações sociais que extrapolam às instituições em si, compondo, assim, uma rede móvel de suportes mútuos, táticas e estratégias afins em estreita ligação com uma situação estratégica complexa numa determinada sociedade. Esta é a lição metodológica essencial que encontramos no "institucionalismo" foucaultiano. Suas análises sobre leprosários e o grande confinamento em História da loucura à formação do dispositivo da sexualidade e o confessionário em $A$ vontade saber, passando, evidentemente, pelo panoptismo de Vigiar e punir atestam ricamente essa ideia. Neste último, Foucault, categoricamente, afirma: "A disciplina não pode se identificar com uma instituição nem com um aparelho; ela é um tipo de poder, uma tecnologia" (FOUCAULT, 2004: 177).

Dos famosos postulados da analítica do poder, dois destacam exatamente o argumento sugerido anteriormente, ou seja: 1) Não-localização: "o poder se exerce a partir de múltiplos pontos e em meio a relações desiguais e móveis"; 2) Não-titularidade: "o poder não possui um titular (classe ou instituição), as relações de poder veem de baixo, são capilares". Seguindo essa linha de raciocínio, Foucault conclui: "O poder não é uma instituição e nem uma estrutura, não é uma certa potência de que alguns sejam dotados: é o nome dado a uma situação estratégica complexa numa sociedade determinada" (FOUCAULT, 1988: 103).

\section{Considerações finais}

A atenção às múltiplas formas de sujeição que existem e circulam na sociedade e suas relações, isto que é uma verdadeira marca da perspectiva foucaultiana, abre inúmeras vias e possibilidades de pesquisa empírica para a sociologia. A obra foucaultiana tem a oferecer para a ciência da sociedade um consistente "programa de investigação" sobre poder, saber, instituições e sujeito.

Foucault divide com a sociologia um interesse obstinado pelo tempo presente, isto é, no sentido de realizar um diagnóstico crítico sobre a atualidade. Diagnóstico não apenas no sentido de identificar os dilemas específicos e questões 
prementes que têm sua origem em embates e temas de sua sociedade e tempo, senão, sobretudo, de identificar, pela crítica histórica (arqueologia e genealogia) os constrangimentos e limites historicamente configurados que nos determinam, no presente, como sujeito do que pensamos, dizemos e fazemos, e isto com vista a uma ultrapassagem possível desses limites historicamente arbitrários, quer seja na forma de "pensar diferentemente" quer na forma política e ética de estilização e condução da vida por novas formas de ser, recusando a individualização e normalização do poder. Sua obra, como sugeriu o belo título de um artigo escrito por Jürgen Habermas por ocasião de sua morte, é uma "flecha no coração do presente" (HABERMAS, 1994).

Nesse sentido, ele prolonga a vocação original dos clássicos da sociologia: diante das exigências e da singularidade do presente, e movidos por uma poderosa inquietação intelectual, tomar como tarefa irrecusável a interpretação profunda de "nosso tempo", das condições históricas, das práticas culturais e relações sociais que conformam quem somos, o que pensamos e o que fazemos na atualidade. A contribuição foucaultiana para a análise sociológica passa, indubitavelmente, pela problematização histórica das questões do presente, principalmente das práticas institucionalizadas mais evidentes, mais naturalizadas em nosso cotidiano e cultura.

Por isso, o pensamento e a obra de Michel Foucault representam, certamente, um dos principais empreendimentos intelectuais de crítica da sociedade da segunda metade do Século XX. Para muitos, Foucault é o paradigma do pensamento crítico radical do Século XX e Começo do XXI (CASTEL, 2006: 9). Sua intenção de trazer à luz as relações de poder que estruturam a vida social, relações estas que, muitas vezes, somos muito pouco conscientes a propósito de sua arbitrariedade, sua historicidade e de seus efeitos políticos em nosso cotidiano e subjetividade, trouxe ao trabalho intelectual um novo ânimo de denúncia e resistência aos diversos modos de dominação e sujeição social. Não por acaso, o filósofo social Axel Honneth, em um estudo inovador sobre as fases da Teoria Crítica e da Escola de Frankfurt, reconhece em Michel Foucault o responsável pelo principal desenvolvimento teórico - ao lado dos trabalhos de Jürgen Habermas - capaz de dar continuidade e renovar a Teoria Crítica da sociedade (HONNETH, 2009).

Certa vez, Paul Veyne sustentou que Foucault revolucionou a história ao mostrar que não existe objeto, prática, comportamentos, sentimentos que não sejam históricos. Tudo é histórico, tudo o que diz respeito às relações humanas e ao que os seres humanos fazem entre si e sobre si mesmos é histórico. Essa ideia, aventada por Paul Veyne não é, certamente, apenas uma revolução para a história. Que revolução, ou, ao menos, que importantes lições Foucault deixou 
para os sociólogos e para prática sociológica? Esta é uma questão relevante que ainda não foi devidamente enfrentada em todo o seu alcance.

Um primeiro passo é, certamente, melhor compreender a natureza da relação de Foucault com a sociologia, o que tentamos explicitar em algumas de suas nuanças e afinidades eletivas. $\mathrm{O}$ segundo passo seria realizar estudos acerca da recepção das ideias foucaultianas no campo da sociologia a partir de recortes nacionais, isto é, analisar como seus conceitos e perspectiva teórico-metodológica foi capaz de adentrar e se integrar no campo da produção sociológica. No Brasil, dita tarefa foi iniciada por Marcos César Alvarez e retomado recentemente por ele novamente (ALVAREZ, 2002; 2015). Por último, apreender os diferentes programas de investigação (LAKATOS, 1989) que compõem a obra foucaultiana, ${ }^{11}$ cotejando-os teórica e empiricamente com os aportes e pesquisas da sociologia e suas especialidades a fim de neles discutir e criticar subsídios e déficits para a análise sociológica, especialmente de temas como a construção social da realidade, as formas de dominação social, as relações entre instituições sociais, conhecimento e administração da vida cotidiano, o papel do poder e da agência na constituição dos sujeitos, entre outros.

\section{Referências}

ADORNO, S. Monopólio Estatal da Violência na Sociedade Brasileira Contemporânea. In: Miceli, S. et al. (Org.). 0 que ler na ciência social brasileira 1970-2002. São Paulo: Sumaré, 2002, v. IV, p. 267-307.

ALEXANDER, J. O Novo Movimento Teórico. Revista Brasileira de Ciências Sociais, v.02, n.04, p.05-28, jun. 1987 .

Sociología cultural: formas de classificación en las sociedades complejas. Antropos. México: FLACSSO, 2000.

ALVAREZ, M. C. Foucault e a sociologia. Cadernos Ceru, série 2, n. 13, 2002.

. Bacharéis, criminologistas e juristas. Saber jurídico e Nova Escola Penal no Brasil. São Paulo: Método, 2003.

11 Em minha dissertação (FREIRE, 2014) explorei o que intitulei de programa de investigação foucaultiano da dominação a partir de quatro unidades de análise: constituição do sujeito, saber, poder e verdade. A tese defendida consistiu na ideia de que a dominação, no pensamento de Foucault, é definida nos termos das principais pressuposições teórico-metodológicas da analítica do poder, isto é, da relação intrínseca com o cerne do projeto filosófico foucaultiano - a constituição do sujeito -, a interdependência entre saber e poder enquanto dimensão essencial e opaca das formas de dominação moderna e, por último, o vínculo entre dominação e produção de discursos de verdade. Nesse sentido, as possíveis contribuições foucaultianas para a análise sociológica foram avaliadas em função desse recorte no programa de investigação da dominação. Todavia, conforme destacado, a obra de Foucault comporta outros programas de investigação. 
. Michel Foucault e a Sociologia: aproximações e tensões. Estudos sociológicos. Araraquara, v.20 n.38 p.15-33 jan.-jun. 2015.

ARON, R.; FOUCAULT, M. Dialogues. Paris: Nouvelles Éditions Lignes, 2007.

BACHELARD, G. A formação do espírito científico: contribuição para uma psicanálise do conhecimento. Rio de Janeiro: Contraponto, 1996.

BENTO, B. A reinvenção do corpo: sexualidade e gênero na experiência transexual.

Rio de Janeiro: Garamond, 2006.

BERTHELOT, J. La construction de la sociologie. Paris: PUF, 1991.

BOURDIEU, P. As Regras da Arte: Gênese e Estrutura do Campo Literário. Trad. Maria

Lúcia Machado. São Paulo: Companhia das Letras, 1992.

BRENNER, N. Foucault's New Functionalism. Theory and Society, n. 23, pp. 679-709, 1994.

CALHOUN, C. et al. Contemporary Sociological Theory. Oxford: Blackwell, 2007.

CASTEL, R. Crítica social. Radicalismo o reformismo político. In. Fernando Álvarez

Uría y Julia Varela (coords.). Pensar y resistir. La sociología crítica después de

Foucault. Ediciones en Ciencias Sociales-Círculo de las Bellas Artes, Madrid: 2006.

CLEGG, S. Foucault, Power and Organizations. In: A. McKinlay\& K. Starkey (Eds)

Foucault, Management and Organization Theory, Sage, 1998.

COSTA, J. F. Ordem médica e norma familiar. Rio de Janeiro: Graal, 1979.

DELEUZE, G. Foucault. São Paulo: Brasiliense, 2005.

ERIBON, D. Michel Foucault, 1926-1984. São Paulo. Companhia das Letras, 1990.

. Michel Foucault e seus contemporâneos. Rio de Janeiro: Jorge Zahar, 1996.

FOUCAULT, M. Doença mental e psicologia. Rio de Janeiro: Tempo Brasileiro, 1984.

. História da sexualidade - a vontade de saber. Rio de Janeiro: Graal, 1988.

O sujeito e o poder. In. DREYFUS, H.; RABINOW, P. Michel Foucault, uma

trajetória filosófica: para além do estruturalismo e da hermenêutica. Rio de Janeiro: Forense Universitária, 1995.

. A Vida: a Experiência e a Ciência. In: Ditos \& Escritos. Arqueologia das ci-

ências e histórias dos sistemas de pensamento humana (Vol. II). Rio de janeiro:

Forense Universitária, 2000a, p. 352-353.

. Filosofia e Psicologia. In: Ditos \& Escritos: Problematização do Sujeito: Psico-

logia, Psiquiatria e Psicanálise (Vol. I). Rio de Janeiro: Forense Universitária, 2002, p. 220-231.

As palavras e as coisas. São Paulo: Martins Fontes, 200ob.

. Vigiar e Punir: o nascimento da prisão. Petrópolis: Vozes, 2004.

A verdade e as formas jurídicas. Rio de janeiro: Nau, 2005.

. A ética do cuidado de si como prática da liberdade. In: Ditos \& Escritos: Ética, sexualidade e política (Vol. V). Rio de Janeiro: Forense Universitária, 2006. 
. As técnicas de si. Tradução de Karla Neves e Wanderson Flor do Nascimento, 2010. Dits et écrits. Paris: Gallimard, 1994b. v. IV, p. 783-813, Disponível em: <http:// www.filoesco.unb.br/foucault>. Acesso em: 30 abr. 2018.

. O que são as Luzes? In: Ditos \& Escritos: Arte, Epistemologia, Filosofia e História da medicina (VII). Rio de Janeiro: Forense universitária, 2011, p 259-268.

As malhas do poder. In: Ditos \& Escritos: Segurança, Penalidade e Prisão. Rio de Janeiro: Forense Universitária, 2012.

FREIRE, A. T. F. Michel Foucault e a dominação: contribuições para a sociologia. 2014. Dissertação - Programa de Pós graduação em Ciências Sociais Universidade Federal do Rio Grande do Norte, Natal, 2014.

GARLAND, D. Punishment and modern society: a study in social theory. Oxford, Claredon Press, 1995.

GIDDENS, A. A transformação da intimidade: sexualidade, amor e erotismo nas sociedades modernas. São Paulo: Ed. Unesp, 1993.

Política, Sociologia e Teoria Social: encontros com o pensamento clássico e contemporâneo. São Paulo. Unesp, 1998.

Modernidade e identidade. Rio de Janeiro: Jorge Zahar Ed., 2002.

HABERMAS, J. Taking Aim at Heart of the Present. In: Critique and Power. Recasting the Foucault/Habermas Debate. Ed. Michael Kelly. Cambridge: MIT Press, 1994.

HALPERIN, D. Saint Foucault - A Gay Hagiagraphy. New York: Oxford University Press, 1995.

HONNETH, A. Crítica Del Poder: Fases em la reflexión de uma Teoria Crítica de la sociedad. Madrid: Machado, 2009.

LAHIRE, B. El espírito sociológico. Buenos Aires: Manantiel, 2006a.

A cultura dos indivíduos. Porto Alegre: Artes Médicas, 2006b.

LAKATOS, I. La metodologia de los programas de investigacion científica. Madrid: Alianza Editorial, 1989.

MACHADO, R. et al. Danação da norma. Rio de Janeiro: Graal, 1978.

MISKOLCI, R. Teoria Queer e a sociologia: o desafio de uma analítica da normalização. Sociologias (UFRGS), v. 21, p. 150-1982, 2009.

NISBET, R. La Formacíon del Pensamiento Sociológico. Buenos Aires: Amorrortu Editores, 1969.

PAIVA, A. C. S. Reservados e invisíveis: o ethos íntimo das parcerias homoeróticas. Campinas: Pontes Editores, 2007.

PETERSEN, A. Re-defining the subject? The influence of Foucault on the sociology of health and illness. Health Sociology Review: Vol. 3, No. 1, pp. 119-131. 1993.

POWER, M. Foucault and Sociology. Annual Review of Sociology, vol. 37, p. 35-56, 2011. 
RAGO, M. O efeito-Foucault na historiografia brasileira. Tempo Social; Rev. Sociol. USP, S. Paulo, 7(1-2): 67-82, outubro de 1995.

ROSE, N. Inventing ourselves: psychology, power and personhood. New York: Cambridge University Press, 1996.

. The Politics of life itself: biomedicine, power and subjectivity in the twentieth-first century. Princeton, New Jersey: Princeton University Press, 2007.

SALLA, F. A retomada do encarceramento: as masmorras high tech e a atualidade do pensamento de Michel Foucault. Cadernos da F.F. C (UNESP), Marília, v. 9, n.1, p. 35-58, 2001.

SEIDMAN, S. The social construction of sexuality. Contempary Societies. State University of New York, 2003.

SENNETT, R. Carne e pedra: o corpo e a cidade na civilização ocidental. Rio de Janeiro: Record, 2003.

SOUSA FILHO, A. A política do conceito: subversiva ou conservadora? - crítica à essencialização do conceito de orientação sexual. Revista Bagoas: Estudos gays - gêneros e sexualidades, Natal, v. 03, n. 04, p. 59-77, 2009.

TURNER, B. S. The Body and Society. Sage Pub. London: 1996.

VARELA, J.; ALVAREZ-URIA, F. Arqueologia de la escuela. Madrid: Espanha. Ediciones La Piqueta, 1993.

VEYNE, P. Foucault revoluciona a história. In: Como se escreve a história; Foucault revoluciona a história. Brasília: UnB, 2008a.

. História, sociologia, história total. In: Como se escreve a história; Foucault revoluciona a história. Brasília: UnB, 2008b.

Foucault, o pensamento, a pessoa. Lisboa: Texto \& Grafia, 2009.

WEBER, M. Ensayos sobre sociología de la religión. Madri: Taurus, vol. 1, 2001.

Recebido em 13/03/2016

Aprovado em 19/02/2018

\section{Como citar este artigo:}

FREIRE, Alyson Thiago Fernandes. Afinidades eletivas: Foucault, a sociologia e os sociólogos. Contemporânea - Revista de Sociologia da UFSCar, v. 8, n. 1, jan.- jun. 2018, pp. 265-288. 